\section{Import of animal viruses opposed after accident at laboratory}

\section{Sydney}

OPPOSITION to the import of animal viruses into Australia has intensified following an accident at the controversial Australian Animal Health Laboratory (AAHL). A potentially dangerous poultry virus seems likely to have been carried from the laboratory in the form of a human infection.

The accident occurred when a laboratory technician neglected to check that a filter was in place in the apparatus she was using to concentrate a solution of the virus. Live virus sprayed onto her face and hair. After showering twice, she was told she could leave the laboratory but that she might develop conjuctivitis, a symptom of the disease in humans. Three days later the symptoms appeared.

The technician was counselled to keep away from poultry but any possibility that she could have passed on the information arouses strong emotions among Australian farmers. The virus was the AlbistonGorrie strain of Newcastle disease which devastated Australian chicken farms in

\section{Old jobs, new rates}

\section{London}

BRITISH nuclear industry safety inspectors have been given a pay rise to bring their salaries more into line with what they could get from industry or the private sector, to try to bring a halt to chronic staff shortages.

The independent Advisory Committee on the Safety of Nuclear Installations has

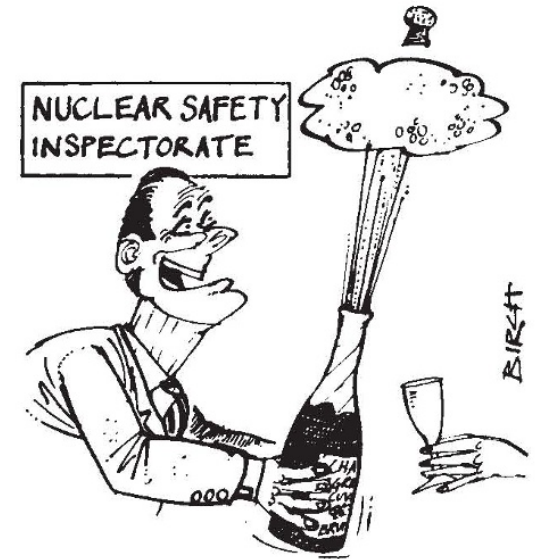

recommended an increase in Nuclear Installations Inspectorate staffing by 50 per cent on present levels, to 150 , to cope with present and future workloads. The inspectorate is reviewing the safety of Britain's ageing Magnox reactors, especially any earthquake risk, and it has also been involved in time-consuming reviews of the recently-approved Sizewell B pressurized water reactor.

Kathy Johnston the 1930 s. Today the poultry industry employs 25,000 people and is worth A $\$ 640$ million a year.

The AAHL facility was designed to provide Australia with the capacity rapidly to diagnose exotic animal diseases. Right from the start it has met opposition because it has not only collected together disease agents from around the country but also imported, for the purposes of research, diseases that do not exist in Australia. Three diseases deadly to pigs have been imported in the past six weeks. Built at a cost of $\mathrm{A} \$ 160$ million at Geelong, near Melbourne, the facility is thought to be the most advanced microbiological containment facility of its type in the world, and escape of biological agents to be impossible. The New South Wales Farmer's Association will now seek a Federal Court injunction to restrain any further import of live exotic viruses.

\section{Toronto}

IN an effort to reverse the trend of Canadian dependence on imported high technology, the province of Ontario will spend $\$ 200$ million over five years to create seven "centres of excellence". Eight Ontario universities and 100 Canadian companies will take part. The competition for money from this new source is intended to stimulate cooperation between Ontario universities and industries.

The seven centres, each a joint venture involving up to six universities and 15 companies, were selected from 28 pro"Premier Council", which is directing a $\$ 1,000$-million fund supporting science and technology research in Ontario. The proposals were reviewed by a 13 -member international panel, advised by 98 external reviewers from Japan, Britain, France, Canada and the United States. John Polanyi, the University of Toronto's recent Nobel prize-winner in chemistry, called the programme "a major and imaginative undertaking".

Polanyi will be a principal investigator at the Centre for Advanced Laser and Lightwave Research at the University of Toronto, which will concentrate on novel lasers and sources, lasers in medicine and related areas. The other planned centres are the Institute for Space and Terrestrial Science at York Univeristy, the Centre for Integrated Manufacturing at McMaster University, the Centre for Groundwater Research and the Centre for Information posals submitted to Ontario's new
According to Dr Bill Snowdon, chief of the AAHL, the decision to send the laboratory technician home was made because no case of the virus being transmitted from human to animal, or human to human, has ever been recorded. Snowdon regrets that the technician was not given more extensive counselling, as it has come to light that tissues she used to wipe her eyes were thrown into a rubbish bin. The virus could be picked up by wild birds that forage on rubbish tips.

AAHL does not have the facilities or the power to quarantine workers. But Snowdon now says, given public reaction to the incident, that he would think twice about letting the person concerned go home if a similar accident occurred. $\mathrm{He}$ has ordered an independent inquiry into a number of breaches of AAHL procedure that may have contributed to the accident. Many questions have already been raised: the acting chief of AAHL was not notified until five days after the accident, the chief veterinary officer of Victoria was not notified for a week, and the poultry industry was not notified at all. Charles Morgan

\title{
Major funding for new Canadian centres of excellence
}

Technology, both at the University of Waterloo, the Centre for Materials Research at Queen's University, and the Telecommunications Research Institute of Ontario at both Carleton University and the University of Ottawa.

Each centre will be subject to a rigorous review after 30 months and, according to the provincial government, if the mandate is not followed, money will be pulled out. J. Fraser Mustard, chairman of the evaluation panel, says that the success of each programme will be judged by the extent to which the research contributes to industrial growth in Ontario. In announcing the initiative at a press conference on 19 June, Ontario Premier David Peterson said that, "we don't want research sitting on the laboratory table. We want it applied to the real world." Peterson also said that he believed the new centres will allow the creation of a "critical mass" of the best available minds.

R.W. Nicholls, director of York University's Centre for Research in Experimental Space Science, says the new centres will "support long-term fundamental and applied research, but must spin off the research into industry. There will be a visble industrial benefit in a few years time." Nicholls said the project was "big.... As far as York is concerned, we are talking about $\$ 40$ milion over 5 years. That's several times more than the current budget of our entire faculty of science. This project will certainly put Ontario on the world map."

Russell McNeil 